\title{
Habilidade competitiva entre biótipos de Cyperus difformis L. resistente ou suscetível a herbicidas inibidores de ALS e destes com arroz irrigado
}

\author{
Taísa Dal Magro ( $\left.{ }^{1 *}\right)$; Carlos Eduardo Schaedler ( $\left.{ }^{2}\right)$; Lisiane Camponogara Fontana ( ${ }^{2}$ ); \\ Dirceu Agostinetto ( $\left.{ }^{2}\right)$; Leandro Vargas ( ${ }^{3}$ ) \\ (') Universidade Federal de Pelotas (UFPel), Faculdade de Agronomia Eliseu Maciel (FAEM), Programa de Pós-Graduação em \\ Fitossanidade, Caixa Postal 354, 96010-900 Pelotas (RS). \\ (2) UFPel, FAEM, Departamento de Fitossanidade, 96010-900 Pelotas (RS). \\ (3) Embrapa Trigo, 99001-970 Passo Fundo (RS). \\ (*) Autora correspondente: taisadm@yahoo.com.br
}

Recebido: 8/abr./2009; Aceito: 14/set./2010

\section{Resumo}

Em biótipos de plantas daninhas resistentes a herbicidas pode haver menor habilidade competitiva, comparativamente aos biótipos suscetíveis. O objetivo da pesquisa foi investigar a habilidade competitiva entre biótipos de Cyperus difformis L. resistente ou suscetível a herbicidas e destes com arroz irrigado. Foram realizados quatro experimentos em casa de vegetação, em 2007 e 2008, em delineamento inteiramente casualizado, com quatro repetições, sendo os tratamentos do primeiro arranjado em série aditiva e dos demais arranjados em série de substituição. Em cada experimento, as proporções entre biótipos de C. difformis resistente e suscetível e destes com arroz foram de 100:0, 75:25, 50:50, 25:75 e 100:0\%, com população total de 1060 plantas $\mathrm{m}^{-2}$. As variáveis avaliadas foram área foliar, estatura e matéria seca da parte aérea. A análise da competitividade foi realizada por aplicação de diagramas e interpretações dos índices de competitividade. Biótipos de C. difformis resistente e suscetível a herbicidas inibidores de ALS, em geral, possuem habilidade competitiva equivalente; a cultura do arroz, com a cultivar BRS Querência, tem habilidade competitiva superior a C. difformis resistente ou suscetível a herbicidas inibidores de ALS; para a cultura do arroz, a competição intraespecífica é mais importante, enquanto para $C$. difformis resistente ou suscetível a herbicidas inibidores de ALS, a mais importante é a competição interespecífica.

Palavras-chave: competição, Oryza sativa, série de substituição.

\section{Competitive ability between biotypes of Cyperus difformis L. resistant or susceptible to ALS-inhibitor herbicide and those with flooded rice}

\begin{abstract}
Biotypes of weeds resistant to herbicides may have lower competitive ability compared to susceptible biotypes. The objective of the study was to investigate the relative competitive ability between biotypes of Cyperus difformis L. resistant or susceptible to ALS-inhibitor herbicides and with rice. Four experiments were carried out under greenhouse, in a completely randomized design with four replications, in 2007 and 2008. Treatments were arranged in additive series and replacement series assay. In each series, the proportion among C. difformis resistant and susceptible plants related to rice were: 100:0, 75:25, 50:50, 25:75 and 100:0\%, always with a total population of 1060 plants $\mathrm{m}^{-2}$. Leaf area, plant height and shoot dry mass were evaluated. Competitiveness statistical analysis consisted in applying diagrams to the replacement series and alternative interpretations of the competitiveness indexes. In general, biotypes $C$. difformis resistant and susceptible to ALS-inhibitors herbicides have equivalent competitive ability; the rice cultivar BRS Querência has superior competitive ability in relation to C. difformis resistant or susceptible to ALS-inhibitors herbicides; and for rice, the intraspecific competition is more important, while for $C$. difformis resistant or susceptible to ALS-inhibitors herbicides, the most important is the interspecific competition.
\end{abstract}

Key words: competition, Oryza sativa, replacement series. 


\section{INTRODUÇÃO}

A competição entre plantas é uma interação negativa, na qual as plantas envolvidas concorrem por recurso que se encontra em suprimento escasso, resultando em prejuízo mútuo (RAdosevich et al., 1997) ou modificam seu desenvolvimento, quando comparadas com plantas crescendo isoladamente (Blanco, 1972).

As culturas podem responder de duas maneiras à competição com plantas daninhas: tolerância, que consiste na habilidade em manter a produtividade em situação de competição; ou supressão, que se refere à capacidade da cultura em reduzir o crescimento das plantas daninhas por efeito de interferência (JANNINK et al., 2000).

Para determinar as interaçóes competitivas entre plantas daninhas e culturas tem sido utilizados vários métodos, abrangendo os fatores população, proporção de espécies e arranjo espacial (RADOSEvich, 1987), em quatro tipos gerais de experimentos: aditivo, sistemático, superfície de resposta e série substitutiva. Em cada método experimental, a resposta de uma espécie é utilizada para descrever a influência da(s) outra(s) na associação, através de variáveis como produtividade, taxa de germinação e mortalidade de plantas, entre outras.

Os experimentos em série de substituição são os mais usados para a determinação das relaçóes de competição, pois possibilitam o estudo da competição inter e intraespecífica (Roush et al., 1989). A premissa desse tipo de experimento é que as produtividades das misturas possam ser determinadas em comparação à da monocultura. Esses experimentos visam indicar qual espécie é mais competitiva (Cousens, 1991).

Quando culturas são semeadas em mistura com plantas daninhas, com variação na proporção de plantas, poderá haver vantagem tanto das culturas como das plantas daninhas em competição, variaçôes decorrentes das espécies presentes. Em casos estudados, as plantas daninhas superaram as culturas, como observado para capim-arroz em competição com arroz (AgostinetTo et al., 2008); arroz-vermelho competindo com arroz (FLECK et al., 2008); e nabo competindo com soja (BiAnCHI et al., 2006) ou com trigo (Rigoli et al., 2008). Em outras situaçóes, a cultura superou as plantas daninhas, como pode ser observado para azevém competindo com trigo (Rigoli et al., 2008) ou ocorreu competitividade equivalente, como observado para capim-colchão competindo com soja (LóPEs-Ovejero et al., 2007).

Em lavouras de arroz irrigado, entre as espécies pertencentes à família Cyperaceae em que há dificuldade de controle, Cyperus difformis L. tem-se destacado pela resistência a herbicidas inibidores da enzima acetolactato sintase (ALS) (HEAP, 2009).

As formas de manejo de plantas daninhas resistentes, são baseadas em apenas dois processos biológicos que são a alteração da pressão de seleção e, ou, seleção reversa.
Assim, estudos relacionados com a habilidade competitiva permitem auxiliar nas estratégias de manejo para biótipos resistentes, uma vez que plantas daninhas resistentes a herbicidas com competitividade inferior às culturas poderão ser suprimidas.

A hipótese dessa pesquisa é que o biótipo de $C$. difformis resistente a herbicidas inibidores de ALS possui menor habilidade competitiva quando ocorre em proporçáo populacional equivalente à do biótipo suscetível; esses permitem menor habilidade competitiva quando ocorrem em proporção populacional equivalente ao arroz irrigado.

$\mathrm{O}$ objetivo da pesquisa foi investigar a habilidade competitiva entre biótipos de Cyperus difformis L. resistente ou suscetível a herbicidas inibidores de ALS e desses com arroz irrigado, utilizando-se o método de série de substituição para abordagem da investigação.

\section{MATERIAL E MÉTODOS}

Foram realizados quatro experimentos em casa de vegetação, no município de Capão do Leão (RS), em 2007 e 2008, em delineamento completamente casualizado, com quatro repetiçóes. Os experimentos foram alocados em vasos, preenchidos com solo, com capacidade volumétrica para $1 \mathrm{~L}$ e diâmetro da superfície de $18 \mathrm{~cm}$.

No experimento I, em série aditiva, foram avaliados monocultivos de $C$. difformis suscetível a herbicidas inibidores de ALS (oriundo de Itajaí no Estado de Santa Catarina) e arroz, cultivar BRS Querência, com o objetivo de determinar a população de plantas $\mathrm{m}^{-2}$ a partir da qual a área foliar (AF) e a matéria seca da parte aérea (MSPA) por unidade de área tornam-se independentes da população, de acordo com a "lei de produção final constante" (RAdosevich et al., 1997). As populaçóes testadas foram $1,2,4,8,12,16,20$ e 24 plantas vaso ${ }^{-1}$ (equivalentes a 88, 177, 353, 707, 1060, 1413, 1767 e 2120 plantas $\mathrm{m}^{-2}$ ).

As variáveis $\mathrm{AF}\left(\mathrm{cm}^{2}\right)$ e MSPA ( $\mathrm{g}$ planta $\left.{ }^{-1}\right)$ foram analisadas aos 40 dias após a emergência (DAE). A AF foi determinada com auxílio de determinador de AF Modelo $3100 \mathrm{C}$ e a MSPA foi quantificada pela pesagem da parte aérea das plantas após secagem em estufa a $60^{\circ}$ até massa constante. $\mathrm{Na}$ análise dos dados utilizou-se o método da recíproca da produção por planta para determinar a produção de AF e MSPA constante, a qual foi obtida com a população de 1060 plantas $\mathrm{m}^{-2}$ para a cultura e para a planta daninha (dados não apresentados).

Os experimentos II, III e IV foram realizados em série de substituição, com população de 12 plantas vaso ${ }^{-1}(1060$ plantas $\mathrm{m}^{-2}$ ), determinada no experimento I. Em cada série, as proporçôes entre plantas de $C$. difformis resistente (oriundo de Meleiro no Estado de Santa Catarina) e suscetível (experimento II), $C$. difformis resistente e arroz (experimento III) e $C$. difformis suscetível e arroz (experimento IV), foram de 100:0 (estande puro do primei- 
ro competidor), $75: 25,50: 50,25: 75$ e 0:100\% (estande puro do segundo competidor). Para o estabelecimento das populaçóes, a semeadura foi realizada em densidades superiores às desejadas, com posterior transplante.

As variáveis avaliadas foram AF, estatura de planta (EST) e MSPA aos 40 DAE. A AF e MSPA foram determinadas conforme descrito no experimento I e a EST foi avaliada tomando-se o comprimento da planta desde o nível do solo até o ápice, com o limbo foliar distendido.

Para análise dos dados referentes às variáveis AF, EST e MSPA, utilizou-se o método da análise gráfica da produtividade relativa (Cousens, 1991; RAdosevich, 1987).

A produtividade relativa $(\mathrm{PR})$ das variáveis avaliadas foi calculada da seguinte forma: $\mathrm{PR}=$ média da mistura I média da monocultura. A produtividade relativa total (PRT) foi representada pela soma das PR dos competidores em cada experimento. Quando a PR resultou em linha reta, considerou-se que a habilidade da espécie ou biótipo em interferir sobre a outra era equivalente. Quando a PR resultou em uma linha côncava, definiu-se ocorrer prejuízo no crescimento de um ou de ambos os competidores. Quando a linha apresentada pela PR foi convexa, definiuse como ocorrência de benefício no crescimento de um ou de ambos os competidores. A PRT sendo igual a um (linha reta), significou que ocorreu competição pelo(s) mesmo(s) recurso(s); sendo superior a um (linha convexa), não ocorreu competiçáo, devido ao suprimento de recursos superar a demanda ou porque as espécies possuíam diferentes demandas pelo(s) recurso(s) do meio; e, quando inferior a um (linha côncava), significou ocorrer antagonismo, havendo prejuízo mútuo ao crescimento de ambas as espécies (Cousens, 1991).

Calcularam-se ainda os índices de competitividade relativa (CR), coeficientes de agrupamento relativo (K) e de competitividade (C) na proporçáo de $50 \%$ dos competidores. A CR representa o crescimento comparativo do biótipo (1) (C. difformis resistente ou suscetível) em relação ao competidor (2) (C. difformis suscetível ou arroz); $\mathrm{K}$ indica a dominância relativa de uma espécie ou biótipo sobre a outra; e C, qual espécie ou biótipo manifesta-se mais competitivo (Cousens, 1991). A interpretação conjunta desses valores indica com maior segurança a competitividade das espécies ou biótipos envolvidos. Uma espécie ou biótipo é mais competitivo que o outro quando: $\mathrm{CR}>1$; $\mathrm{K}_{\mathrm{cr}}>\mathrm{K}_{\mathrm{cs}}, \mathrm{K}_{\mathrm{cr}}>\mathrm{K}_{\mathrm{a}}$ ou $\mathrm{K}_{c s}>\mathrm{K}_{\mathrm{a}}$; e, C > 0 (Hoffman e BuHLER, 2002). Os índices foram calculados através das seguintes equaçóes: $\mathrm{CR}=\mathrm{PR}_{\mathrm{cr}} / \mathrm{PR}_{\mathrm{cs}}, \mathrm{CR}=\mathrm{PR}_{\mathrm{cr}} / \mathrm{PR}$ ou $\mathrm{CR}$ $=\mathrm{PR}_{c s} / \mathrm{PR}_{\mathrm{a}} ; \mathrm{K}_{\mathrm{cr}}=\mathrm{PR}_{\mathrm{cr}} /\left(1-\mathrm{PR}_{\mathrm{cr}}\right), \mathrm{K}_{\mathrm{cs}}=\mathrm{PR}_{\mathrm{cs}} /\left(1-\mathrm{PR}_{\mathrm{cs}}\right)$ ou $\mathrm{K}_{\mathrm{a}}=\mathrm{PR}_{\mathrm{a}} /(1-\mathrm{PR})$; e $\mathrm{C}=\mathrm{PR}_{\mathrm{cr}}-\mathrm{PR}_{\mathrm{cs}} \mathrm{C}=\mathrm{PR}_{\mathrm{cr}}-\mathrm{PR}_{\mathrm{a}}$ ou $\mathrm{C}=\mathrm{PR}_{\mathrm{cs}}-\mathrm{PR}_{\mathrm{a}}$ (Cousens e O'NeILl, 1993 apud Bianchi et al., 2006). Os índices CR, K e C foram considerados diferentes, quando no mínimo em duas proporçōes, ocorressem significâncias pelo teste t (BIANCHI et al., 2006).

Para análise estatística da PR, primeiro foram calculadas as diferenças para os valores de PR obtidos nas propor- çóes de 25\%, 50\% e 75\% de plantas, em relação aos valores pertencentes às retas hipotéticas obtidas nas respectivas proporçóes (Passini et al., 2003). O teste $t(p \leq 0,05)$ foi utilizado para testar as diferenças nos índices estimados em relação à reta hipotética (PAssini et al., 2003; HoffMAN e BuHler, 2002). As hipóteses de nulidade utilizadas para testar as diferenças de $\mathrm{PR}$ e $\mathrm{C}$ foram iguais a zero $\left(\mathrm{H}_{0}=0\right)$; para PRT e $\mathrm{CR}$, as médias foram iguais a um $\left(\mathrm{H}_{0}=1\right)$; para o índice $\mathrm{K}$, as médias das diferenças entre $\mathrm{K}_{\mathrm{t}}$ e $\mathrm{K}_{\mathrm{c}}$ foram iguais a zero $\left[\mathrm{H}_{0}=\left(\mathrm{K}_{\mathrm{t}}-\mathrm{K}_{\mathrm{c}}\right)=0\right]$.

Os resultados para AF, EST e MSPA das plantas de $C$. difformis resistente e suscetível e arroz, expressos em valores médios por planta, foram submetidos à análise de variância. Quando o teste F indicou significância ( $\mathrm{p} \leq 0,05)$, as médias dos tratamentos foram comparadas pelo teste de Dunnett $(\mathrm{p} \leq 0,05)$, considerando-se as respectivas monoculturas como testemunhas.

\section{RESULTADOS E DISCUSSÃO}

A análise gráfica dos resultados anotados para a combinação de $C$. difformis resistente e suscetível (experimento II) referente a PR e PRT das variáveis AF, EST e MSPA demonstrou, em geral, que em ambos os biótipos os valores foram inferiores aos das retas estimadas (Figura 1).

O biótipo resistente promoveu redução em todas as variáveis avaliadas quando estava na mesma proporção de plantas e para as variáveis EST e MSPA quando participou com a maior e menor proporção de plantas respectivamente (Figura 1; Tabela 1). Já no biótipo suscetível a redução ocorreu somente para a MSPA na maior proporção de plantas. Com relação a diferenças para a PRT, observouse, em todas as simulaçóes, que ela foi inferior a 1 , porém com diferenças entre os valores dos desvios esperados e observados somente para a AF na proporção 50:50 e MSPA nas proporçóes 50:50 e 25:75 (Figura 1; Tabela 1). Esses resultados evidenciam que houve competição entres os biótipos pelos mesmos recursos, quando se encontravam nas mesmas proporções de plantas, ocorrendo, em geral, antagonismo entre os biótipos (Cousens, 1991).

$\mathrm{O}$ crescimento relativo do biótipo de $C$. difformis resistente, representado pelo índice CR, foi inferior a 1 , para todas as variáveis estudadas, não havendo diferenças, o que demonstrou que os biótipos se equivalem em crescimento (Tabela 2). Os índices $\mathrm{K}$ e C não representaram diferença, comprovando que os biótipos se equivalem quanto à sua habilidade competitiva (Tabela 2). Uma possível causa para ocorrência de competitividade equivalente entre os biótipos são as semelhanças morfofisiológicas dos biótipos que, por serem da mesma espécie (C. difformis), comportam-se semelhantemente e exploram o mesmo nicho ecológico.

A análise gráfica referente as variáveis $\mathrm{AF}, \mathrm{EST}$ e MSPA demonstrou que o arroz foi mais competitivo que 

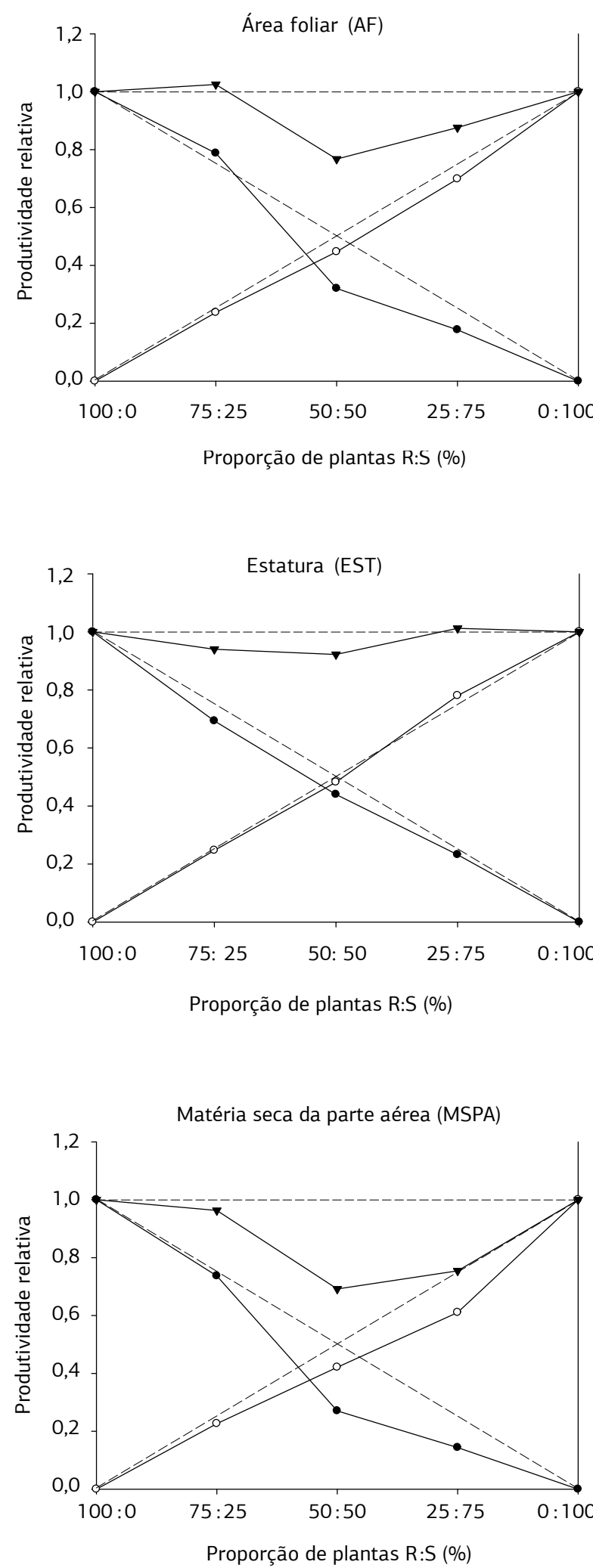

Figura 1. Produtividade relativa (PR) e total (PRT) para área foliar, estatura e matéria seca da parte aérea do biótipo de $C$. difformis resistente e suscetível a herbicidas inibidores de ALS. Círculos cheios $(\bullet)$ representam a PR do biótipo resistente $(\mathrm{R})$, círculos vazios $\left({ }^{\circ}\right)$ a PR do biótipo suscetível $(S)$ e triângulo $(\boldsymbol{\nabla})$ indica a PRT. As linhas tracejadas referem-se às produtividades relativas hipotéticas, quando não ocorre interferência. Capão do Leão (RS), 2008. os biótipos de $C$. difformis resistente ou suscetível a herbicidas inibidores de ALS (experimentos III e IV), sendo a PR do arroz representada pela linha convexa e a dos biótipos por linha côncava (Figura 2). As diferenças de PR para o arroz, em geral, foram significativas para todas as variáveis, quando as proporçóes de plantas da cultura foi superior ou equivalente aos biótipos de $C$. difformis (Tabela 1). Esse fato expressa benefício da cultura e prejuízo ao competidor e que a competiçáo entres espécies ocorre pelos mesmos recursos do ambiente, onde a cultura aproveita de forma mais eficiente que a planta daninha. Por sua vez, os biótipos de $C$. difformis resistente ou suscetível a herbicidas propiciaram menor produção das variáveis avaliadas em todas as proporçôes de plantas, à exceção da variável EST quando os biótipos participaram com a menor ou maior proporção de plantas. Já Para a PRT dos biótipos competindo com o arroz, a qual foi representada por linhas. côncavas, para todas as variáveis avaliadas e os valores inferiores a 1 (Figura 2), constata-se que houve prejuízo mútuo ao crescimento, ou seja, a competição entre as espécies foi pelos mesmos recursos. Porém, diferenças estatísticas entre os valores esperados e estimados somente foram observados para a competição entre o biótipo suscetível e arroz em proporção equivalente de plantas, para todas as variáveis e para o biótipo resistente e a cultura para a variável $\mathrm{AF}$, quando a cultura participou com a menor proporçáo de plantas (Tabela 1).

O crescimento do arroz em relaçáo aos biótipos de C. difformis resistente ou suscetível, indicado pelo índice $\mathrm{CR}$, foi superior a 1, para as variáveis estudadas, havendo dominância da cultura em relação à planta daninha, conforme indicado pelos índices $\mathrm{Ke} \mathrm{C}$ (Tabela 2). Em geral, a cultura é mais competitiva que as plantas daninhas, pois o efeito da infestante não ocorre apenas pela habilidade competitiva individual, mas, principalmente pela população total de plantas (VILÀ et al., 2004). Resultados semelhantes foram observados para a cultura do trigo quando em competição com azevém (Rigolı et al., 2008) e feijão competindo com capim-marmelada (PAssins et al., 2003). No entanto, nem sempre a cultura é mais competitiva que a planta daninha, em alguns casos a planta daninha foi mais competitiva que a cultura, como pode ser observado na competição de nabo com soja (BIANCHI et al., 2006) ou com trigo (Rigoli et al., 2008) e arroz-vermelho competindo com arroz (FLECK et al., 2008).

A convivência entre biótipos de $C$. difformis (experimento II) evidenciou a ocorrência de competição intraespecífica para o biótipo resistente, principalmente quando a proporção do biótipo suscetível predomina (50:50 e 25:75) para as variáveis estudadas, ou seja, em $56 \%$ das comparaçôes o biótipo resistente causou menor produção para as variáveis comparativamente ao seu monocultivo (Tabela 3 ). Já para o biótipo suscetível não se verificou diferença com relação aos monocultivos para nenhuma das variáveis estudadas. Assim, considerando-se que a redução observada 
Tabela 1. Diferenças relativas de produtividade para as variáveis área foliar, estatura e matéria seca da parte aérea; e produtividade relativa total, nas proporçôes 75:25, 50:50 e 25:75 de biótipos de $C$. difformis resistente a herbicidas inibidores de ALS em competição com suscetível e destes com arroz, cultivar BRS Querência. Capão do Leão (RS), 2008

\begin{tabular}{|c|c|c|c|}
\hline \multirow{3}{*}{ Experimento } & \multicolumn{3}{|c|}{ Proporções de plantas } \\
\hline & $75: 25$ & $50: 50$ & $25: 75$ \\
\hline & \multicolumn{3}{|c|}{ Área foliar (AF) } \\
\hline Experimento II - resistente & $0,04( \pm 0,04)^{\mathrm{ns}}$ & $-0,18( \pm 0,03)^{*}$ & $-0,07( \pm 0,03)^{\mathrm{ns}}$ \\
\hline Experimento II - suscetível & $-0,01( \pm 0,01)^{\mathrm{ns}}$ & $-0,05( \pm 0,04)^{\mathrm{ns}}$ & $-0,05( \pm 0,07)^{\mathrm{ns}}$ \\
\hline Experimento II - total & $1,02( \pm 0,03)^{\mathrm{ns}}$ & $0,77( \pm 0,02)^{*}$ & $0,88( \pm 0,07)^{\mathrm{ns}}$ \\
\hline Experimento III - resistente & $-0,37( \pm 0,05)^{*}$ & $-0,29( \pm 0,02)^{*}$ & $-0,15( \pm 0,02)^{*}$ \\
\hline Experimento III - arroz & $0,19( \pm 0,04)^{*}$ & $0,20( \pm 0,05)^{*}$ & $0,05( \pm 0,03)^{\mathrm{ns}}$ \\
\hline Experimento III - total & $0,82( \pm 0,02)^{*}$ & $0,91( \pm 0,04)^{\mathrm{ns}}$ & $0,90( \pm 0,06)^{\mathrm{ns}}$ \\
\hline Experimento IV - suscetível & $-0,29( \pm 0,05)^{*}$ & $-0,31( \pm 0,01)^{*}$ & $-0,14( \pm 0,01)^{*}$ \\
\hline Experimento IV - arroz & $0,19( \pm 0,05)^{*}$ & $0,18( \pm 0,04)^{*}$ & $0,13( \pm 0,05)^{\mathrm{ns}}$ \\
\hline \multirow[t]{2}{*}{ Experimento IV - total } & $0,90( \pm 0,09)^{\mathrm{ns}}$ & $0,87( \pm 0,04)^{*}$ & $0,99( \pm 0,06)^{\mathrm{ns}}$ \\
\hline & \multicolumn{3}{|c|}{ Estatura (EST) } \\
\hline Experimento II - resistente & $-0,05( \pm 0,02)^{*}$ & $-0,06( \pm 0,01)^{*}$ & $-0,02( \pm 0,01)^{\mathrm{ns}}$ \\
\hline Experimento II - suscetível & $-0,003( \pm 0,01)^{\mathrm{ns}}$ & $-0,02( \pm 0,02)^{\mathrm{ns}}$ & $-0,03( \pm 0,02)^{\mathrm{ns}}$ \\
\hline Experimento II - total & $0,94( \pm 0,02)^{\mathrm{ns}}$ & $0,92( \pm 0,03)^{\mathrm{ns}}$ & $1,01( \pm 0,03)^{\mathrm{ns}}$ \\
\hline Experimento III - resistente & $-0,14( \pm 0,07)^{\mathrm{ns}}$ & $-0,11( \pm 0,02)^{*}$ & $-0,05( \pm 0,02)^{\mathrm{ns}}$ \\
\hline Experimento III - arroz & $0,03( \pm 0,01)^{\mathrm{ns}}$ & $0,04( \pm 0,01)^{*}$ & $0,01( \pm 0,02)^{\mathrm{ns}}$ \\
\hline Experimento III - total & $0,89( \pm 0,08)^{\mathrm{ns}}$ & $0,92( \pm 0,03)^{\mathrm{ns}}$ & $0,97( \pm 0,03)^{\mathrm{ns}}$ \\
\hline Experimento IV - suscetível & $-0,07( \pm 0,03)^{\mathrm{ns}}$ & $-0,12( \pm 0,01)^{*}$ & $-0,04( \pm 0,02)^{\mathrm{ns}}$ \\
\hline Experimento IV - arroz & $0,02( \pm 0,01)^{\mathrm{ns}}$ & $0,002( \pm 0,03)^{\mathrm{ns}}$ & $0,002( \pm 0,02)^{\mathrm{ns}}$ \\
\hline \multirow[t]{2}{*}{ Experimento IV - total } & $0,95( \pm 0,03)^{\mathrm{ns}}$ & $0,89( \pm 0,03)^{*}$ & $0,98( \pm 0,03)^{\mathrm{ns}}$ \\
\hline & \multicolumn{3}{|c|}{ Matéria seca da parte aérea (MSPA) } \\
\hline Experimento II - resistente & $-0,01( \pm 0,03)^{\mathrm{ns}}$ & $-0,23( \pm 0,03)^{*}$ & $-0,11( \pm 0,03)^{*}$ \\
\hline Experimento II - suscetível & $-0,02( \pm 0,01)^{\mathrm{ns}}$ & $-0,08( \pm 0,04)^{\mathrm{ns}}$ & $-0,14( \pm 0,01)^{*}$ \\
\hline Experimento II - total & $0,96( \pm 0,03)^{\mathrm{ns}}$ & $0,69( \pm 0,02)^{*}$ & $0,75( \pm 0,04)^{*}$ \\
\hline Experimento III - resistente & $-0,47( \pm 0,05)^{*}$ & $-0,38( \pm 0,02)^{*}$ & $-0,19( \pm 0,02)^{*}$ \\
\hline Experimento III - arroz & $0,27( \pm 0,06)^{*}$ & $0,31( \pm 0,06)^{*}$ & $0,18( \pm 0,06)^{\mathrm{ns}}$ \\
\hline Experimento III - total & $0,81( \pm 0,09)^{\mathrm{ns}}$ & $0,93( \pm 0,05)^{\mathrm{ns}}$ & $0,98( \pm 0,08)^{\mathrm{ns}}$ \\
\hline Experimento IV - suscetível & $-0,37( \pm 0,05)^{*}$ & $-0,38( \pm 0,00)^{*}$ & $-0,18( \pm 0,01)^{*}$ \\
\hline Experimento IV - arroz & $0,25( \pm 0,06)^{*}$ & $0,22( \pm 0,03)^{*}$ & $0,18( \pm 0,06)^{*}$ \\
\hline Experimento IV - total & $0,88( \pm 0,10)^{\mathrm{ns}}$ & $0,84( \pm 0,03)^{*}$ & $1,00( \pm 0,06)^{\mathrm{ns}}$ \\
\hline
\end{tabular}

ns: Não significativo; *: significativo pelo teste $\mathrm{t}(\mathrm{p} \leq 0,05)$. Valores entre parênteses representam os erros padrōes das médias.

Tabela 2. Índices de competitividade entre biótipos de $C$. difformis resistente a herbicidas inibidores de ALS em competição com suscetível e destes com arroz, cultivar BRS Querência, expressos por competitividade relativa (CR) e coeficientes de agrupamento relativo (K) e de agressividade (C). Capão do Leão (RS), 2008

\begin{tabular}{|c|c|c|c|c|}
\hline \multicolumn{5}{|c|}{ Experimento II - resistente:suscetível } \\
\hline & CR $\left({ }^{4}\right)$ & $\operatorname{Kcr}\left({ }^{5}\right)$ & Kcs & $C\left(^{6}\right)$ \\
\hline $\mathrm{AF}\left({ }^{1}\right)$ & $0,75( \pm 0,12)^{\mathrm{ns}}$ & $0,48( \pm 0,11)^{\mathrm{ns}}$ & $0,84( \pm 0,28)$ & $-0,13( \pm 0,07)^{\mathrm{ns}}$ \\
\hline EST $\left({ }^{2}\right)$ & $0,92( \pm 0,03)^{\mathrm{ns}}$ & $0,79( \pm 0,06)^{\mathrm{ns}}$ & $0,94( \pm 0,17)$ & $-0,04( \pm 0,02)^{n s}$ \\
\hline MSPA ( $\left.{ }^{3}\right)$ & $0,69( \pm 0,14)^{\mathrm{ns}}$ & $0,38( \pm 0,07)^{\mathrm{ns}}$ & $0,76( \pm 0,07)$ & $-0,15( \pm 0,07)^{\mathrm{ns}}$ \\
\hline \multicolumn{5}{|c|}{ Experimento III - resistente:arroz } \\
\hline & CR & Kcr & Ka & C \\
\hline AF & $3,37( \pm 0,06)^{*}$ & $0,27( \pm 0,04)^{*}$ & $2,18( \pm 0,60)$ & $0,49( \pm 0,07)^{*}$ \\
\hline EST & $1,37( \pm 0,03)^{*}$ & $0,67( \pm 0,06)^{*}$ & $1,15( \pm 0,04)$ & $0,14( \pm 0,01)^{*}$ \\
\hline MSPA & $6,41( \pm 0,03)^{*}$ & $0,15( \pm 0,02)^{*}$ & $3,46( \pm 0,75)$ & $0,68( \pm 0,06)^{*}$ \\
\hline \multicolumn{5}{|c|}{ Experimento IV - suscetível:arroz } \\
\hline & CR & Kcs & Ka & C \\
\hline AF & $3,02( \pm 0,02)^{*}$ & $0,31( \pm 0,01)^{*}$ & $3,21( \pm 0,42)$ & $0,47( \pm 0,04)^{*}$ \\
\hline EST & $1,26( \pm 0,05)^{*}$ & $0,72( \pm 0,03)^{*}$ & $1,00( \pm 0,12)$ & $0,10( \pm 0,03)^{*}$ \\
\hline MSPA & $4,94( \pm 0,01)^{*}$ & $0,19( \pm 0,01)^{*}$ & $2,28( \pm 0,45)$ & $0,61( \pm 0,04)^{*}$ \\
\hline
\end{tabular}

$\left({ }^{1}\right)$ Área foliar, $\left({ }^{2}\right)$ Estatura, $\left({ }^{3}\right)$ Matéria seca da parte aérea; $\left({ }^{4}\right)$ Competitividade relativa; $\left({ }^{5}\right)$ Coeficiente de agrupamento relativo para o biótipo resistente $(\mathrm{r})$, suscetível $(\mathrm{s})$ e arroz (a); $\left(^{(}\right)$Coeficiente de agressividade. ${ }^{\text {ns }}$ :Não significativo; ${ }^{*}$ : Significativo pelo teste $t(\mathrm{p} \leq 0,05)$. Valores entre parênteses representam os erros padrốes das médias. 

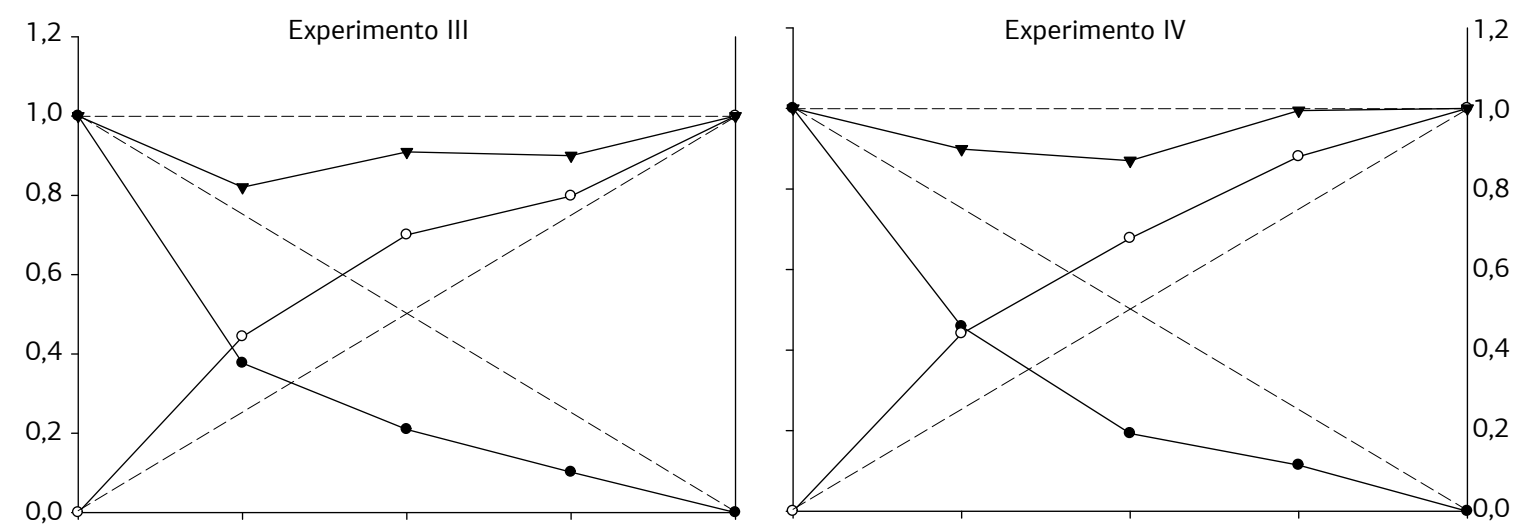

Estatura (EST)
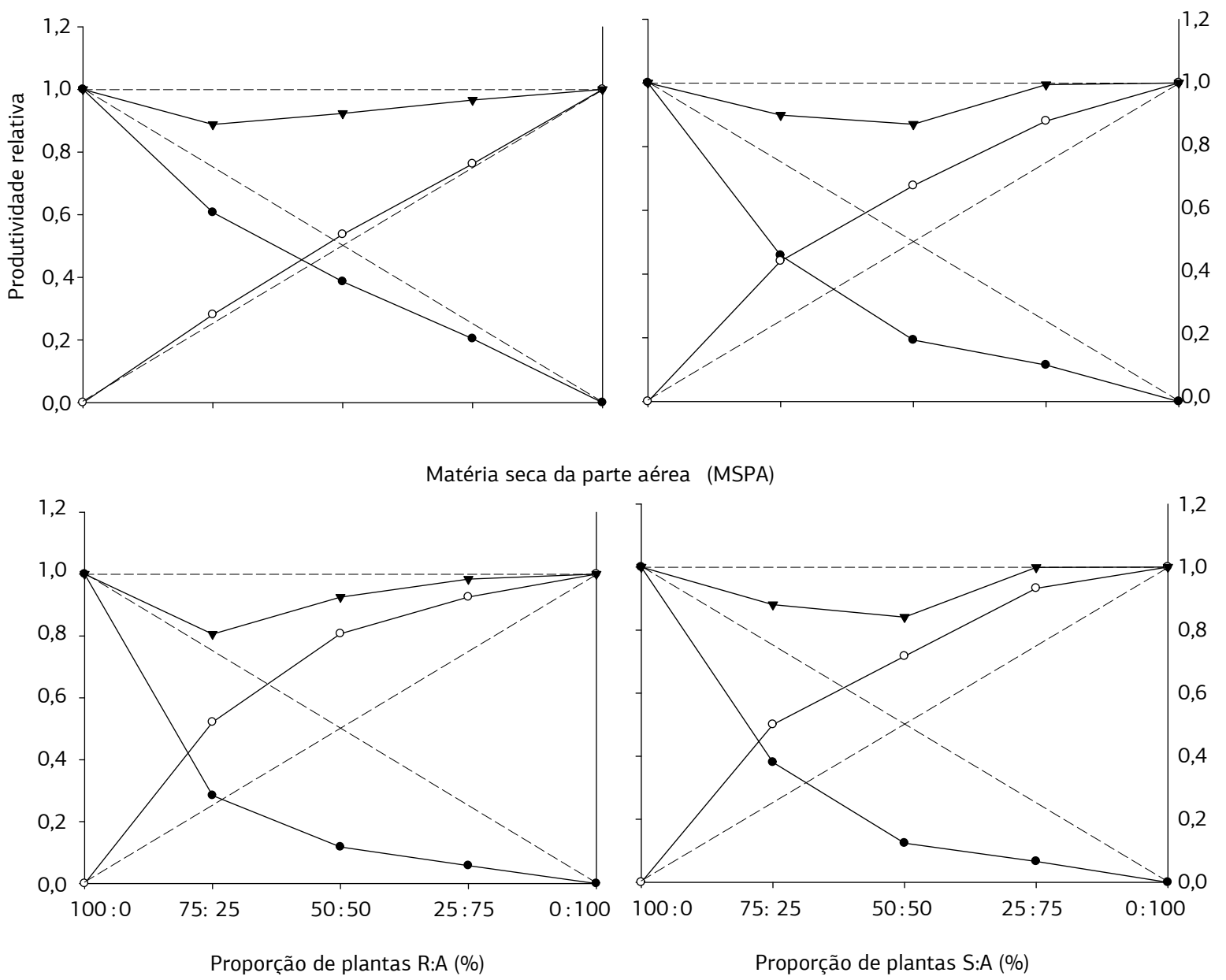

Figura 2. Produtividade relativa (PR) e total (PRT) para área foliar, estatura e matéria seca da parte aérea do biótipo de C. difformis resistente $(\mathrm{R})$ ou suscetível $(\mathrm{S})$ a herbicidas inibidores de ALS com arroz (A). Círculos cheios $(\bullet)$ representam a PR do biótipo resistente ou suscetível, círculos vazios $\left(^{\circ}\right)$ representam a PR do arroz, cultivar BRS Querência e triângulo ( $)$ indica a PRT. As linhas tracejadas referemse às produtividades relativas hipotéticas, quando não ocorre interferência. Capão do Leão (RS), 2008.

para o biótipo resistente ocorreu em aproximadamente metade das comparaçôes somente e que os índices de competitividade relativa se equivaleram, pode-se inferir que os biótipos possuem similar habilidade competitiva.

A convivência de $C$. difformis resistente ou suscetível com arroz (experimentos III e IV, respectivamente) de- monstrou, em geral, reduçáo das variáveis avaliadas para os biótipos e que a competição interespecífica foi a mais acentuada (Tabela 3). Assim, os biótipos de Cyperus preferem em sua vizinhança uma planta da própria espécie em relação a uma planta de arroz. Por sua vez, o arroz promoveu, em geral, incremento para as variáveis AF e MSPA, 
Tabela 3. Resposta de biótipo de C. difformis resistente a herbicidas inibidores de ALS em competição com biótipo suscetível, e destes com arroz, cultivar BRS Querência. Capão do Leão (RS), 2008

\begin{tabular}{|c|c|c|c|c|c|c|}
\hline \multirow{3}{*}{ Experimento } & \multicolumn{5}{|c|}{ Proporções de plantas (\%) } & \multirow[b]{2}{*}{ C.V.(\%) } \\
\hline & 100:0 & $75: 25$ & $50: 50$ & $25: 75$ & $0: 100$ & \\
\hline & \multicolumn{6}{|c|}{ Área foliar (AF) } \\
\hline Experimento II - resistente & 20,2 & $21,3^{\text {ns }}$ & $13,0^{*}$ & $14,4^{*}$ & - & 15,2 \\
\hline Experimento II - suscetível & - & $16,1^{\text {ns }}$ & $15,5^{\text {ns }}$ & $16,4^{\text {ns }}$ & 17,3 & 20,4 \\
\hline Experimento III - resistente & 17,7 & $8,9^{*}$ & $7,4^{*}$ & $7,2^{*}$ & - & 22,3 \\
\hline Experimento III - arroz & - & $17,1^{\text {ns }}$ & $22,5^{*}$ & $28,5^{*}$ & 16,1 & 15,4 \\
\hline Experimento IV - suscetível & 18,2 & $11,1^{*}$ & $7,0^{*}$ & $8,3^{*}$ & - & 15,0 \\
\hline \multirow[t]{2}{*}{ Experimento IV - arroz } & - & $18,5^{\text {ns }}$ & $21,4^{*}$ & $18,5^{\text {ns }}$ & 15,8 & 13,1 \\
\hline & \multicolumn{6}{|c|}{ Estatura (EST) } \\
\hline Experimento II - resistente & 19,1 & $17,7^{\text {ns }}$ & $16,8^{*}$ & $17,8^{\text {ns }}$ & - & 6,4 \\
\hline Experimento II -suscetível & - & $19,2^{\text {ns }}$ & $18,7^{\text {ns }}$ & $20,2^{\text {ns }}$ & 19,4 & 7,5 \\
\hline Experimento III -resistente & 18,0 & $14,5^{\text {ns }}$ & $13,9^{\text {ns }}$ & $14,7^{\text {ns }}$ & - & 16,1 \\
\hline Experimento III - arroz & - & $23,5^{\text {ns }}$ & $24,8^{\text {ns }}$ & $25,9^{\text {ns }}$ & 23,1 & 6,4 \\
\hline Experimento IV -suscetível & 18,7 & $16,9^{\text {ns }}$ & $14,4^{*}$ & $15,7^{*}$ & - & 9,2 \\
\hline \multirow[t]{2}{*}{ Experimento IV - arroz } & - & $24,0^{\text {ns }}$ & $23,6^{\mathrm{ns}}$ & $25,7^{\text {ns }}$ & 23,5 & 8,5 \\
\hline & \multicolumn{6}{|c|}{ Matéria seca da parte aérea (MSPA) } \\
\hline Experimento II - resistente & 0,17 & $0,17^{\text {ns }}$ & $0,09^{*}$ & $0,10^{*}$ & - & 17,4 \\
\hline Experimento II -suscetível & - & $0,11^{\text {ns }}$ & $0,12^{\text {ns }}$ & $0,12^{\text {ns }}$ & 0,14 & 19,9 \\
\hline Experimento III -resistente & 0,14 & $0,05^{*}$ & $0,03^{*}$ & $0,03^{*}$ & - & 28,8 \\
\hline Experimento III - arroz & - & $0,15^{\text {ns }}$ & $0,20^{*}$ & $0,25^{*}$ & 0,12 & 19,5 \\
\hline Experimento IV -suscetível & 0,15 & $0,07^{*}$ & $0,04^{*}$ & $0,04^{*}$ & - & 17,3 \\
\hline Experimento IV - arroz & - & $0,17^{\text {ns }}$ & $0,20^{\text {ns }}$ & $0,27^{*}$ & 0,14 & 18,9 \\
\hline
\end{tabular}

ns: Nåo significativo; *: Significativo em relaçăo à respectiva testemunha (100\%) pelo teste de Dunnett ( $\mathrm{p} \leq 0,05)$.

quando participou com igual ou superior proporção de plantas, demonstrando que a cultura prefere competir com a planta daninha em relação à competiçáo intraespecífica. Resultados similares foram observados por LAMEGO et al. (2010) em que biótipos de Bidens subalternans resistentes e suscetíveis a herbicidas inibidores de ALS, também tiveram habilidade competitiva equivalente.

Especulava-se que biótipos de $C$. difformis resistentes a herbicidas tivessem menor capacidade de aproveitar os nutrientes do meio. Os resultados observados nos experimentos não permitem comprovar a hipótese, pois somente em determinadas proporçôes, o biótipo de $C$. difformis resistente causou menor produção para as variáveis avaliadas. Entretanto, quando os biótipos estão competindo com o arroz, eles disputam o mesmo nicho e a cultura apresentou-se como melhor competidora pelos recursos do meio. Outros estudos demonstraram a superioridade da cultura em competir com as plantas daninhas, como observado para biótipos de capim-marmelada competindo com acultura do feijão (PAssini et al., 2003) e azevém com a cultura do trigo (Rigoli et al., 2008).

É importante ressaltar que experimentos substitutivos são inadequados para predizer a dinâmica populacional de duas espécies ou biótipos em concorrência ao longo do tempo (Cousens, 1991). Também, este método é empírico e não pode ser aplicado em campo, pois a proporção de planta no campo é variada e poderá haver a ocorrência de outras espécies no mesmo espaço e, como os experimentos foram encerrados aos $40 \mathrm{DAE}$, o tempo poderá ser insuficiente para a manifestação de eventuais diferenças.

\section{CONCLUSÃO}

Biótipos de $C$. difformis resistente e suscetível a herbicidas inibidores de ALS, em geral, têm habilidade competitiva equivalente. A cultura do arroz, com a cultivar BRS Querência, possui habilidade competitiva superior à $C$. difformis resistente ou suscetível aos herbicidas inibidores de ALS. Para a cultura do arroz, a competição intraespecífica é mais importante, enquanto para $C$. difformis resistente ou suscetível a herbicidas inibidores de ALS, a mais importante é a competição interespecífica.

\section{AGRADECIMENTOS}

Ao Conselho Nacional de Desenvolvimento Científico e Tecnológico - CNPq, pela concessão de bolsa de produtividade científica.

\section{REFERÊNCIAS}

AGOSTINETTO, D.; GALON, L.; MORAES, P.V.D.; RIGOLI, R.P.; TIRONI, S.P.; PANOZZO, L.E. Competitividade relativa entre cultivares de arroz irrigado e biótipo de capim-arroz (Echinochloa spp.). Planta Daninha, v.26, p.757-766, 2008. 
BIANCHI, M.A.; FLECK, N.G.; LAMEGO, F.P. Proporção entre plantas de soja e plantas competidoras e as relaçóes de interferência mútua. Ciência Rural, v.36, p.1380-1387, 2006.

BLANCO, H.G. A importância dos estudos ecológicos nos programas de controle das plantas daninhas. O Biológico, v.38, p.343-350, 1972.

COUSENS, R. Aspects of the design and interpretation of competition (interference) experiments. Weed Technology, v.5, p.664-673, 1991.

FLECK, N.G.; AGOSTINETTO, D.; GALON, L.; SCHAEDLER, C.E. Competitividade relativa entre cultivares de arroz irrigado e biótipo de arroz-vermelho. Planta Daninha, v.26, p.101-111, 2008.

HEAP, I. The international survey of herbicide resistant weeds. Disponível em: <http://www.weedscience.org>. Acesso em 8/ jan./2009.

HOFFMAN, M.L.; BUHLER, D.D. Utilizing Sorghum as functional model of crop-weed competition. I. Establishing a competitive hierarchy. Weed Science, v.50, p.466-472, 2002.

JANNINK, J.L.; ORF, J.A; JORDAN, N.R.; SHAW, R.G. Index selection for weed suppressive ability in soybean. Crop Science, v.40, p.1087-1094, 2000.

LAMEGO, F.P.; BURGOS, N.R.; VIDAL, R.A. Competitive ability of ALS resistant and susceptible Bidens subalternans. In: WEED SCIENCE SOCIETY OF AMERICA ANNUAL MEETING, 2010, Denver. Abstracts. Denver: WSSA, 2010.
LÓPES-OVEJERO, R.F.; NOVO, M.C.S.S.; CARVALHO, S.J.P.; NICOLAI, M.; CHRISTOFFOLETI, P.J. Crescimento e competitividade de biótipos de capim-colchão resistente e suscetível aos herbicidas inibidores da acetil coenzima A carboxilase. Pesquisa Agropecuária Brasileira, v.42, p.1-8, 2007.

PASSINI, T.; CHRISTOFFOLETI, P.J.; YADA, I.F.U. Competitivity of the common-bean plant relative to the weed alexandergrass [Brachiaria plantaginea (Link) Hitch.]. Scientia Agricola, v.60, p.259-268, 2003.

RADOSEVICH, S.; HOLT, J.; GHERSA, C. Weed ecology: implications for management. 2.ed. New York: Willey, 1997. 589p. (Cap. 6: Physiological aspects of competition)

RADOSEVICH, S.R. Methods to study interactions among crops and weeds. Weed Technology, v.1, p.190-198, 1987.

RIGOLI, R.P.; AGOSTINETTO, D.; SCHAEDLER, C.E.; DAL MAGRO, T.; TIRONI, S.P. Habilidade competitiva relativa do trigo (Triticum aestivum) em convivência com azevém (Lolium multiflorum) ou nabo (Raphanus raphanistrum). Planta Daninha, v.26, p.93-100, 2008.

ROUSH, M.L.; RADOSEVICH, S.R.; WAGNER, R.G.; MAXWELL, B.D.; PETERSEN, T.D. A comparison of methods for measuring effects of density and proportion in plant competition experiments. Weed Science, v.37, p.268-275, 1989.

VILÀ, M.; WILLIAMSON, M.; LONSDALE, M. Competition experiments on alien weeds with crops: lessons for measuring plant invasion impact? Biological Invasions, v.6, p.59-69, 2004. 